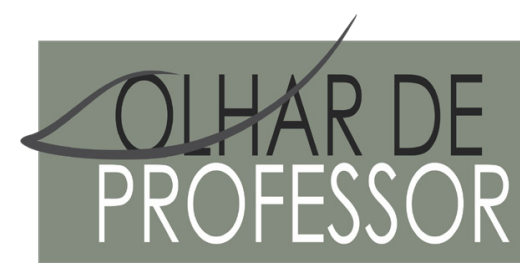

DOI: 10.5212/OLHARPROFR.v.23.2020.15593.209209229632.0720

\title{
POLIITICAS PÚBLLCAS EDUCACIONAIS IMPLICADAS NO BOM DESEMPENHO EM CIÊNCIAS NO PISA: UM ESTUDO COMPARATIVO ENTRE SINGAPURA, FINLÂNDIA E BRASIL
}

\author{
PUBLIC EDUCATIONAL POLICIES IMPLIED IN GOOD PERFORMANCE IN SCIENCES IN PISA: A COMPARATIVE \\ STUDY BETWEEN SINGAPORE, FINLAND AND BRAZIL \\ POLÍTICAS EDUCATIVAS PÚBLICAS IMPLICADAS EN EL BUEN DESEMPEÑO EN CIENCIAS DE PISA: UN \\ ESTUDIO COMPARATIVO ENTRE SINGAPUR, FINLANDIA Y BRASIL
}

\author{
JULIANE BÜHLER* \\ PATRÍCIA IGNÁCIO**
}

\begin{abstract}
Resumo: Os resultados do Programa Internacional de Avaliação de Alunos (PISA) vêm sendo utilizados para promover investigações e debates sobre as práticas e políticas públicas desenvolvidas em países com desempenhos exitosos. Na esteira dessas investigações, o objetivo do estudo foi pesquisar as Políticas Públicas Educacionais envolvidas no Ensino de Ciências implementado no Brasil, em Singapura e na Finlândia; sob o prisma da educação comparada, tomou-se como corpus de análise artigos, teses e dissertações, documentos legais dos países em estudo e relatórios da OCDE. Os achados da pesquisa mostram que Singapura e Finlândia a) possuem sistemas educacionais descentralizados e currículos flexíveis; b) investem mais de 6.000 USD por estudante; c) fortalecem a interação escola e universidade; d) priorizam a formação docente e; e) apresentam uma atraente carreira docente.
\end{abstract}

Palavras-chave: Políticas Públicas. Ensino de Ciências. PISA.

\begin{abstract}
The results of the International Student Assessment Program (PISA) have been used to promote research and debates on public practices and policies developed in countries with successful performances. In the wake of these investigations, the objective of the study was to research the Public Educational Policies involved in Science Teaching implemented in Brazil, Singapore and Finland. Through the prism of comparative education, it took as a corpus of analysis: articles, theses and dissertations; legal documents from the countries under study; and OECD reports. The research findings show that Singapore and Finland: a) have decentralized education systems and flexible curricula; b) invest over 6,000 USD per student; c) strengthen school and university interaction; d) prioritize teacher training; e) have an attractive teaching career.
\end{abstract}

Keywords: Public Policies. Science Teaching. PISA.

Resumen: A través de los resultados del Programa Internacional de Evaluación de Estudiantes (PISA), se está utilizando promover la investigación y el debate relacionado a las prácticas y políticas públicas aplicadas en países con soluciones exitosas. En base a éstas investigaciones se determina que todo ello involucra las enseñanzas de

\footnotetext{
* Mestre em Química Tecnológica e Ambiental, Licenciada em Ciências Exatas pela Universidade Federal do Rio Grande (FURG) e colaboradora do Laboratório de Ensino e Aprendizagem em Ciências Exatas (LEACE). Docente da rede municipal de ensino de Santo Antônio da Patrulha/RS. E-mail: julianebuhler@gmail.com.

** Doutora em Educação pela Universidade Federal de Pernambuco (UFPE), Mestre em Educação em Estudos Culturais pela Universidade Luterana do Brasil (ULBRA) e Licenciada em Pedagogia pela Universidade do Vale do Rio dos Sinos (UNISINOS). Professora Adjunta na Universidade Federal do Rio Grande (FURG), atuando nos cursos de Licenciatura em Ciências Exatas, Licenciatura em Pedagogia EAD e no Programa de Pós-Graduação em Ensino de Ciências Exatas. Líder do Grupo de Estudos e Pesquisa em Educação, Pedagogias e Sociedade (GEEPES) e coordenadora do Laboratório de Ensino e Aprendizagem em Ciências Exatas (LEACE). E-mail: patriciaignacio.furg@gmail.com.
} 
las Ciencias ejecutadas en Brasil, Singapur y Finlandia. Con esta primicia comparada en la Educación, se puede deducir: Que la Educación es descentralizada y flexible; por cuanto se invierte en cada estudiante 6.000 dólares que fácilmente puede generar un crecimiento fortalecido en la integración entre la Escuela y la Universidad; así como también conlleva a la formación de profesores, siendo visto de una manera entusiasta ejemplar para que los jóvenes opten por obtener una facultad o carrera Universitaria de ésta naturaleza (Educación).

Palabras-clave: Políticas Públicas. Enseñanza de las Ciencias. PISA.

\section{INTRODUÇ̃̃O}

Nos últimos anos, avaliações externas têm balizado o que se tem compreendido como padrão de desempenho da educação mundial através de um ranking que expõe a performance de alunos do mundo inteiro. Essas avaliações foram criadas por meio de critérios e conhecimentos estabelecidos por órgãos responsáveis e acabam por desenvolver um conjunto de parâmetros, por meio dos quais se tem compreendido sobre as competências e os saberes considerados válidos. Além disso, estipulam como padrões as Políticas Públicas Educacionais e os processos de ensino e aprendizagem desenvolvidos nos países mais bem posicionados.

Uma das principais avaliações internacionais de larga escala é o Programa Internacional de Avaliação de Alunos (PISA), um programa de avaliação sistemática e comparada que iniciou nos anos 2000. Atualmente, o sistema de avaliação PISA é reconhecido internacionalmente como o maior agregador, em termos de quantidade de conhecimento, dos modelos educativos de diferentes países. O PISA pode ser compreendido como um dispositivo de política do conhecimento; do inglês knowledge policy, seus resultados vêm sendo utilizados para analisar problemas educacionais e promover debates sobre políticas públicas em contextos nacionais, uma vez que se propõe a apoiar e participar no trabalho de coordenação de ações públicas na educação (CARVALHO, 2009; CARVALHO, 2016; VILLANI; OLIVEIRA, 2018).

Carvalho (2012) afirma que o PISA constitui-se como uma ferramenta embasada em conhecimento e sendo produtora de conhecimento, reunindo dados técnicos, sociais e pedagógicos capazes de impactar, em diferentes níveis, a criação e a implementação de Políticas Públicas Educacionais. No âmbito deste artigo, debruça-se sobre as Políticas Públicas Educacionais que favorecem o Ensino de Ciências, estabelecendo uma análise comparativa entre as Políticas Públicas Educacionais implementada no Brasil, em Singapura e na Finlândia.

O Brasil participou desde a primeira edição do PISA em 2000 (ênfase: Leitura), ano em que ficou em último lugar entre os países avaliados (BRASIL, 2001). Em 2003 (Matemática), com a participação de 41 países, o Brasil ficou em penúltimo lugar (OCDE, 2004). Na terceira edição do PISA, em 2006 (Ciências), com a participação de 57 países, a posição brasileira foi de $52^{\mathrm{a}}$ (BRASIL, 2008). No ano de 2009 (Leitura), 65 países participaram do PISA, sendo o Brasil o 53º dentre eles (OCDE, 2010b). Em 2012 (Matemática) houve a participação de 65 países, a posição do Brasil foi a de $58^{\circ}$ lugar (OCDE, 2014).

Com relação à área das Ciências, em 2006 o Brasil ocupou a 52a colocação e em 2015, ficou entre os dez últimos do ranking, em um total de 75 países (OCDE, 2016b). Cabe ressaltar que os conhecimentos de Ciências exigidos pelo PISA envolvem Física, Química, Biologia, Ciências da Terra e do Espaço.

No ano de 2015 participaram do PISA 23.141 alunos brasileiros de 841 escolas: 81,96\% dos avaliados apresentaram conhecimento entre os níveis 1 e 2, muito abaixo da média dos outros países. Menos de 20\% dos jovens brasileiros alcançaram os níveis mais elevados (de 3 a 6). Em contrapartida, a maior parte dos alunos dos demais países da Organização para a Cooperação e Desenvolvimento Econômico (OCDE) encontram-se nos níveis de 3 a 6. De acordo com os critérios do PISA, no nível 1 os estudantes possuem limitado conhecimento científico e são capazes de apresentar explicações e conclusões científicas óbvias. No nível 2, os alunos possuem conhecimentos científicos razoáveis, sendo capazes de refletir, interpretar e solucionar problemas de forma direta e linear (MARÔCO et al., 2016).

Muitas podem ser as causas do fracasso brasileiro no PISA. Estudos sobre os fatores que implicam no desempenho comparativamente baixo do Brasil demonstram que os resultados, para além de expressar 
os erros dos estudantes, ocorrem porque a maioria dos alunos brasileiros não consegue chegar ao final da prova devido à dificuldade dos estudantes em resolver as questões iniciais. Segundo Sassaki, Di Pietra, Menezes Filho e Komatsu (2018), isso pode estar relacionado à lentidão para entender o enunciado e para desenvolver o raciocínio sobre a resposta. Matos e Ferrão (2016) afirmam, também, que os dados do PISA expressam os elevados índices de repetência dos estudantes brasileiros. Em 2012, por exemplo, mais de um terço (36\%) dos estudantes na faixa etária dos 15 anos informou ter repetido o ano pelo menos uma vez, sendo que nos países vinculados à OCDE essa média é de 12\%. Essa distorção aluno-ano escolar (ou seja, alunos que estão em anos escolares inferiores às idades correspondentes) mostra que os estudantes aprenderam menos do que os demais participantes da citada avaliação.

Ortigão, Aguilar Júnior e Zucula (2015), analisando dados do PISA de 2012, mostram que, quando o estudante relata ter sido reprovado uma vez, sua média em Matemática diminui cerca de 26 pontos, chegando a uma queda de 86 pontos, se a reprovação ocorreu duas vezes ou mais durante sua trajetória escolar. Para elucidar a questão, em 2015, o Brasil ficou em terceiro lugar entre os países em que os alunos afirmavam ter repetido pelo menos um ano no Ensino Fundamental (36,4\%), atrás apenas da Argélia (68,5\%) e da Colômbia (42,6\%).

O objetivo desse estudo, portanto, foi pesquisar as Políticas Públicas Educacionais envolvidas no Ensino de Ciências, em especial da Química, em dois dos países com os melhores índices no PISA 2015, tendo em vista a identificação de fatores que promovem a construção do conhecimento, oportunizando a possibilidade de encontrar diretrizes que poderão ser institucionalizadas no Brasil, identificadas na comparação com as Políticas Públicas Educacionais desenvolvidas em Singapura e na Finlândia.

Com relação à metodologia, o artigo fundamenta-se na perspectiva da educação comparada, a partir das discussões apresentadas por Nóvoa (1995), Ferreira (2009) e Silva (2016). Nóvoa (1995) situa as pesquisas em educação comparada como um espaço de cooperação e de tomada de decisão política, desenvolvidas por meio de análises e interpretações capazes de antever o desenvolvimento dos fenômenos educativos e, assim, racionalizar ações políticas no campo da educação. A educação comparada permite a análise de problemáticas educativas dentro de uma região geográfica, de um determinado espaço-tempo educativo, mas também possibilita a compreensão das ações econômicas e políticas que ultrapassam as fronteiras dos estados e dos países (FERREIRA, 2009; SILVA, 2016).

Os critérios para a seleção de Singapura e da Finlândia foram: países entre os cinco listados com o melhor desempenho no PISA 2015, diferente localização continental e com Políticas Públicas Educacionais de abordagens díspares.

As categorias escolhidas para análise justificam-se porque se entende que estas estão implicadas no sucesso dos alunos no PISA: sistemas educacionais, investimento em educação, currículo escolar, formação inicial e seleção de professores. Em cada uma delas foram realizadas análises comparativas das Políticas Públicas Educacionais dos três países em estudo.

\section{OS SISTEMAS EDUCACIONAIS DE SINGAPURA, FINLÂNDIA E BRASIL}

Em um dos primeiros movimentos do estudo, mapeou-se os sistemas educacionais dos três países avaliados, utilizando-se dos documentos legais e de relatórios da OCDE e estudos científicos relacionados a cada uma das nações, para a composição de um paralelo.

Singapura, país asiático com o melhor desempenho em todas as áreas do conhecimento avaliadas no PISA 2015, apresenta um dos maiores PIB per capita do mundo. A nação está, atualmente, entre as economias globais mais dinâmicas e favoráveis aos negócios. Com uma população de 5,607 milhões de habitantes e um PIB de 323,9 bilhões de dólares, aproximadamente 3,5\% do PIB é destinado à educação, que conta com 610 mil estudantes (MINISTRY OF EDUCATION SINGAPORE, 2019).

Os resultados do PISA de 2012 para Leitura, Matemática e Ciências mostraram que os alunos em Singapura superaram os estudantes dos Estados Unidos, Reino Unido e Austrália em mais de 40 pontos, o que equivale a mais de um ano inteiro de escolaridade (JERRIM, 2015). O estudo do PISA 2015, sobre resolução colaborativa de problemas, revelou ainda que Singapura tem a maior proporção de melhores 
desempenhos e uma das menores proporções de baixo desempenho (OECD, 2017). Em Singapura, 21\% dos estudantes têm desempenho superior no PISA, o que é mais que o dobro da média geral entre os sistemas educativos participantes.

A república de Singapura apresenta o maior Índice de Desenvolvimento Humano (IDH) dentre os países que compõem o continente asiático, e o sucesso de seus alunos na avaliação internacional está relacionado com o fato de que desde à sua independência, Singapura tem considerado a educação como sua prioridade (OCDE, 2017). Na localidade, o ensino básico é obrigatório para alunos entre 6 e 15 anos (Compulsory Education Act, 2000) e visa a oferecer conhecimento comum capaz de fornecer uma base sólida para o Ensino Superior, além de experiências escolares, que ajudarão a construir a identidade nacional e a incentivar a coesão social (MINISTRY OF EDUCATION SINGAPORE, 2019).

Depois de conquistar a independência do Império Britânico, Singapura, uma pequena ilha sem recursos naturais, sofreu com o subdesenvolvimento e a alta taxa de desemprego. No ano de 1965, o então Ministro da Educação afirmou que, para atingir a real independência e soberania de sua nação, seria necessário utilizar a educação como ferramenta para a união nacional (CHIA, 2015). A partir dos anos de 1960, o governo de Singapura passou a expandir e universalizar o acesso à Educação Básica, desenvolvendo, principalmente, o ensino das Ciências e da Matemática, além do Ensino Técnico e Profissionalizante (SEONG, 2008). Em 1968, foi criado o Departamento de Educação Técnica e os Centros de Treinamentos para Professores, para a formação de profissionais para as áreas demandadas pela indústria.

Durante os anos de 1970, 1980 e 1990, novas reformas ocorreram no sistema educacional, ampliando massivamente o acesso dos alunos ao Ensino Médio, aumentando a necessidade de novos professores e melhorando o desempenho dos alunos. O Novo Sistema Educacional, vigente entre 1974 e 1985, aplicou os conceitos de administração de empresas na padronização e melhoria dos procedimentos escolares, instituindo avaliações internas e externas e auditorias nas escolas. Durante a reforma, em 1998, para o Thinking Schools, Learning Nations (Escolas do Pensamento, Nações da Aprendizagem), a educação voltou-se para o desenvolvimento das capacidades dos alunos, da criatividade e da vontade de aprender; também ocorreu a flexibilização do currículo, ampliando o poder de escolha dos alunos.

Em relação às Políticas Públicas Educacionais, uma primeira aproximação mostra Singapura como um sistema de integração e planejamento, em que os Ministérios do Trabalho, do Desenvolvimento Econômico e da Educação articulam, em conjunto, a concepção de políticas, para que sejam implementadas rapidamente, de forma a responder às demandas do mercado de trabalho (OCDE, 2010a). Quando as políticas relacionadas à educação são elaboradas ou alteradas, sua implementação é bem executada e, principalmente, segue uma fidelidade muito grande ao planejamento devido ao engajamento do Ministério da Educação, do Instituto Nacional de Educação (INE) e dos diretores e professores (AVILA et al., 2012).

Já a Finlândia, localizada no norte do continente europeu, obteve o primeiro lugar na primeira edição do PISA e permaneceu nas primeiras colocações em várias edições, ficando em quinto lugar no PISA 2015. Além disso, dados mostram uma baixa variação relativa da performance dentro da mesma escola e entre as escolas finlandesas, assinalando a equidade do sistema (BASTOS, 2017). Sahlberg (2015) ressalta que, na Finlândia, equidade significa ter um sistema de educação socialmente justo e inclusivo, que ofereça a todos a oportunidade de realizar suas intenções e seus sonhos através da educação.

A Finlândia constituiu-se como democracia parlamentar em meados do século XX. A educação finlandesa tornou-se pública e gratuita, em todos os níveis, a partir de 1921, garantindo pela Constituição Finlandesa (Constitution Act of Finland) o acesso e o direito à educação para todos. Os principais objetivos da educação na Finlândia estão fundamentados em políticas de desenvolvimento sustentável, liberdade e valorização do aprendizado individual, além de igualdade de oportunidades para todos os alunos. Com as reformas implementadas no final da década de 1960, em que o parlamento promulgou uma legislação para criar um novo sistema de Educação Básica, os alunos agora entrariam na escola aos nove anos de idade e permaneceriam até os dezesseis anos.

Em novembro de 1968, o parlamento promulgou a Lei da Educação Básica (Basic Education Act, 1968), criando um novo sistema de Educação Básica, em torno de um modelo comum, introduzindo um sistema escolar abrangente e substituindo o existente, de dois níveis. A educação é gerenciada pelo Ministério da Educação e pelo Conselho Nacional de Educação, os quais visam a implementar e 
aprimorar as finalidades educativas, os conteúdos e métodos do ensino, assim como avaliar o sistema educacional. Compete ao Estado e às autoridades locais o financiamento da educação, sendo que a maioria dos estudantes frequenta o ensino público, uma vez que, a maioria das instituições privadas não diferem das públicas. Segundo o Ministério da Educação da Finlândia, as escolas privadas devem seguir os mesmos princípios, currículo e as qualificações nacionais, tendo como requisitos básicos a confiança e a responsabilidade, já que estas instituições também recebem financiamento público (MINISTRY OF EDUCATION FINLAND, 2018).

Estudos como os de Fuchs e Wößmann (2007), Lee et al. (2014) e Moraes (2017) consideram que o sucesso da educação finlandesa advém de reformas educacionais implantadas desde 1968. Contudo, antes mesmo dos anos de 1960, o princípio básico da educação finlandesa era a igualdade e a equidade de acesso, muito pela influência cultural da Suécia e da Rússia (MEINANDER, 2011). Nas reformas que seguiram, principalmente na década supramencionada, o Parlamento investiu na renovação do Ensino Fundamental e Médio e na formação de professores, aumentando de seis para nove anos a educação obrigatória. Já nos anos de 1990, as reformas proporcionaram a flexibilização dos currículos (os alunos passaram escolher as disciplinas de sua grade curricular), a descentralização da administração do sistema educacional, a substituição do modelo top-down (modelo centralizador de gestão da educação) e a maior autonomia dos professores. Nesse período, o Ministério da Educação deixou de ser o encarregado por todos os processos escolares, de forma que as escolas passaram a desenvolver seus currículos de acordo com as realidades e especificidades locais (OCDE, 2015; VÄLIJÄRVI et al., 2007).

Na Finlândia, as escolas podem construir seus próprios currículos e programas pedagógicos, tendo como base as grades curriculares municipais e nacionais. Em Singapura, a descentralização ocorreu principalmente nas escolas de turno integral, com o objetivo de incentivar o empreendedorismo e a economia do conhecimento. Fuchs e Wößmann (2007), ao examinarem dados do PISA, observaram uma ligação entre a autonomia escolar e o desempenho dos alunos. Para os autores, a autonomia escolar nas decisões curriculares, de contratação, escolha de livros didáticos e na alocação de recursos causa uma melhora no desempenho desses estudantes.

No Brasil, durante a década de 1960, ocorreu a promulgação da Primeira Lei de Diretrizes e Bases da Educação Nacional (LDB, Lei 4.024/61), dividindo o ensino brasileiro em três níveis (primário, médio e superior), em que se instituiu a obrigatoriedade do acesso à escola aos sete anos. A LDB respondeu ao desejo da sociedade brasileira de ampliar o acesso à educação, colocando-a como base para o desenvolvimento industrial do país, necessário para a produção de riquezas e para superar o subdesenvolvimento econômico (MARCHELLI, 2014). Em 1988, começaram as discussões a respeito da nova proposta de LDB, que tramitou na Câmara dos Deputados e no Senado por sete anos. A Lei 9493/96 instituiu a Educação Básica obrigatória e gratuita dos 4 aos 17 anos de idade, compreendendo a Educação Infantil, o Ensino Fundamental, o Ensino Médio e a Educação de Jovens e Adultos.

Em 2014, foi promulgado o Plano Nacional de Educação (Lei no 13.005/2014), o qual propõe a expansão gradativa da oferta de vagas para a Educação Infantil, tendo como meta atender pelo menos metade da demanda por creche até 2024 (BRASIL, 2014). Em 2017, o Ministério da Educação homologou a Base Nacional Comum Curricular (BNCC), cujo objetivo é estabelecer aspectos normativos curriculares, definindo conhecimentos, habilidades e competências necessárias para a Educação Básica.

Segundo dados do UNICEF (2015), o Brasil, pela criação e implementação de políticas públicas educacionais, garantiu o acesso de $93 \%$ de suas crianças e adolescentes à Educação Básica. Além disso, resultados da Pesquisa Nacional por Amostra de Domicílio (PNAD), entre 1990 e 2013, demonstram que o percentual de alunos em idade obrigatória fora da escola caiu 64\%, passando de 19,6\% para 7\% das crianças e adolescentes (BRASIL, 2015).

No Brasil, a descentralização não ocorreu da mesma forma. Ela está ligada, principalmente, à divisão de recursos entre a União, os Estados e os Municípios, na seleção dos professores, piso salarial docente e na construção dos currículos escolares. Ao analisar as linhas de tempo das reformas dos sistemas educacionais dos três países percebe-se que: i) os três passaram de sistemas centralizadores, nos quais o governo era responsável por todas as ações da educação, para sistemas descentralizados; porém, ii) diferentemente do Brasil, Singapura e Finlândia aliaram o processo de descentralização ao aumento da qualidade da formação docente e dos gestores escolares. Para Castro (2016), a descentralização brasileira, 
em vez de trazer uma correlação positiva no desempenho dos alunos, tornou a coordenação da Educação Básica mais complexa e aumentou a disparidade entre diferentes regiões.

Com relação à estrutura do Sistema Educativo e ao gerenciamento dos investimentos, no Brasil, a União, por meio do Ministério da Educação, é responsável pela suplementação e distribuição do financiamento da educação, enquanto os Estados e os Municípios são responsáveis pela universalização da Educação Básica. Em Singapura, são os Ministérios do Trabalho, do Desenvolvimento Econômico e da Educação que estão articulados na implementação de políticas públicas educacionais, além do Instituto Nacional de Educação, que estabelece a comunicação entre o governo e os diretores e professores das escolas. Na Finlândia, a educação é gerida pelo Ministério da Educação e pelo Conselho Nacional de Educação, juntamente com autoridades locais (municipalidades).

\section{INVESTIMENTO EM EDUCAÇÃO}

Autores como Amaral (2015) e Vilela-Ribeiro e Benite (2017) têm demonstrado que existe uma ligação entre o investimento em educação e o sucesso dos alunos no PISA. Seguindo na esteira desse entendimento, nesta seção avaliam-se os investimentos em educação a partir de dados demográficos e do PIB (Produto Interno Bruto) das nações estudadas.

Segundo dados da OCDE (2017), o alto valor atribuído à educação como chave do desenvolvimento econômico fica evidente nas ações dos líderes de Singapura, uma vez que seus investimentos aumentaram para 3,6\% do PIB em 2017, aproximadamente 20\% das despesas totais do governo, perdendo apenas para o Ministério da Defesa, a fim de atender 610 mil estudantes nas 340 escolas do país (MINISTRY OF EDUCATION SINGAPORE, 2019). A população de Singapura é de 5,607 milhões de habitantes e o PIB é de 323,9 bilhões de dólares. A localidade investe em torno de 15.500 dólares por aluno, por ano, nos anos finais do Ensino Fundamental, e em torno de 12.500 dólares nos anos iniciais.

Na Finlândia, despesas com as instituições de ensino em todos os níveis representam 6,5\% do PIB (251 bilhões de dólares), ligeiramente acima da média da OCDE (6,3\%). Nos últimos anos, o país aumentou os gastos em educação em 0,5 pontos percentuais (um pouco acima da média da OCDE, que é de 0,4 pontos percentuais) (OCDE, 2018); quase todos os gastos são com instituições públicas de ensino (97,6\%, em comparação com a média da OCDE, que é de 83,6\%). A Finlândia gasta em torno de 14.500 dólares por aluno, por ano, nas séries finais do Ensino Fundamental, e em torno de 9.500 dólares nas séries iniciais, com seus mais de 560.000 estudantes em 2.341 escolas públicas (VOLMARI, 2019).

Com uma população de 209,3 milhões de habitantes e um PIB de 2,3 trilhões de dólares, o investimento público do Brasil em instituições de ensino é de 5,6\% do PIB, para todos os níveis de ensino combinados (acima da média da OCDE, que é de 5,3\% do PIB). Entre 2010 e 2012, as despesas públicas em instituições de ensino como porcentagem do PIB aumentaram 4\% (em comparação à redução média da OCDE, de 3\%). Em se tratando da despesa pública total em educação, o Brasil aumentou em 7,7 pontos percentuais entre os anos de 2000 e 2012, passando para 17,2\%, bem acima da média da OCDE, que é de $11,6 \%$, e maior do que a maioria dos países da OCDE. Nos anos iniciais, a despesa por estudante (3.095 USD) representa 38\% da média da OCDE e, nos anos finais (2.020 USD), 32\%; as despesas por aluno do ensino superior (10.455 USD) representam 70\% da média da OCDE (15.028 USD) (OCDE, 2015). O Quadro 1 apresenta os dados demográficos e os valores de investimentos de Brasil, de Singapura e da Finlândia em educação. 
QUADRO 1: DADOS DEMOGRÁFICOS E INVESTIMENTOS DE BRASIL, SINGAPURA E FINLÂNDIA EM EDUCAÇÃO.

\begin{tabular}{c|c|c|c|c|c|c}
\hline País & $\begin{array}{c}\text { População } \\
\text { (milhões) }\end{array}$ & $\begin{array}{c}\text { PIB } \\
\text { (USD) }\end{array}$ & $\begin{array}{c}\text { Investimentos } \\
\text { em educação } \\
\text { (USD) }\end{array}$ & $\begin{array}{c}\text { Investimento } \\
\text { por aluno } \\
\text { Anos Iniciais } \\
\text { (USD) }\end{array}$ & $\begin{array}{c}\text { Investimento } \\
\text { por aluno } \\
\text { Anos Finais } \\
\text { (USD) }\end{array}$ & $\begin{array}{c}\text { Número de } \\
\text { estudantes/ } \\
\text { Número de } \\
\text { escolas }\end{array}$ \\
\hline Brasil & 209,3 & $\begin{array}{c}2,3 \\
\text { trilhões }\end{array}$ & $\begin{array}{c}5,6 \% \\
128,8 \text { bilhões }\end{array}$ & 3.095 & 2.020 & $\begin{array}{c}48,5 \text { milhões/ } \\
181,9 \text { mil }\end{array}$ \\
\hline Singapura & 5,607 & $\begin{array}{c}323,9 \\
\text { bilhões }\end{array}$ & $\begin{array}{c}3,6 \% \\
11,6 \text { bilhões }\end{array}$ & 12.500 & 15.500 & $610.000 /$ \\
Finlândia & 5,607 & $\begin{array}{c}251 \\
\text { bilhões }\end{array}$ & $\begin{array}{c}6,5 \% \\
15,0 \text { bilhões }\end{array}$ & 14.500 & 9.500 & $560.000 /$ \\
\hline
\end{tabular}

FONTE: DADOS DA PESQUISA.

Embora a porcentagem do PIB brasileiro destinada à educação seja maior do que a de Singapura e apenas 0,9\% menor do que o investimento da Finlândia, quando se analisam os investimentos em educação por aluno, por ano letivo, pode-se perceber que o Brasil investe um valor significativamente menor em seus educandos em comparação com os outros dois países estudados. Os estudos de Amaral (2015) e Vilela-Ribeiro e Benite (2017) consideram que 6.000 USD de investimento por estudante é o valor mínimo para o bom desempenho dos estudantes no PISA. Segundo os autores, um investimento menor do que esse pode causar um desempenho insatisfatório, como acontece com o Brasil, cujo investimento é praticamente a metade desse valor para os anos iniciais e cerca de um terço nos anos finais. Enquanto Singapura investe mais do que o dobro desse valor nos alunos dos anos finais e iniciais, a Finlândia aplica mais do que o dobro nas séries iniciais e 58\% a mais nas séries finais.

A educação pública em Singapura é quase totalmente financiada pelo governo, a partir das receitas gerais, embora escolas e universidades sejam incentivadas a arrecadar fundos, particularmente para despesas de capital na construção de edifícios ou grandes instalações. As universidades e outras instituições de Ensino Superior são responsáveis por seus próprios orçamentos, submetendo-os ao Ministério da Educação e recebendo, anualmente, subsídios para suas despesas. O Ensino Fundamental é gratuito, porém, diferentemente do Brasil e da Finlândia, há uma taxa nominal para o Ensino Médio e Superior de menos de US \$ 5,00 por mês. A Educação Infantil é subsidiada pelo estado na extensão de cerca de 50\% do custo. As escolas auxiliadas pelo governo recebem um subsídio de até $50 \%$ dos custos de desenvolvimento e uma parte de seus orçamentos operacionais, dependendo do número de alunos matriculados (PASINATO, 2017).

Na Finlândia, via de regra, todas as crianças devem ser educadas na escola mais próxima de onde vivem, mas os pais podem escolher outras escolas. As instituições devem fornecer transporte aos alunos, se o trajeto exceder 5 quilômetros (USTUN; ERYILMAZ, 2018). Por conta dessas políticas, apenas $4 \%$ das crianças finlandesas encontram-se em situação de pobreza e mais de $90 \%$ das mães finlandesas trabalham (CASTRO, 2010). Outra característica importante da educação finlandesa é que ela é gratuita em todos os níveis, incluindo o Ensino Superior (MINISTRY OF EDUCATION FINLAND, 2018).

No Brasil, com a promulgação da LDB, foi instituída a educação obrigatória dos 4 aos 17 anos, e estabelecida a separação normativa, executiva e financeira entre a União, os Estados e os Municípios. A partir dessa Lei, a União ficou responsável pelo Ensino Superior e por executar a distribuição e a suplementação do financiamento da educação, a fim de reduzir as disparidades sociais entre diferentes regiões brasileiras. Por meio do Fundo de Manutenção e Desenvolvimento do Ensino Fundamental (FUNDEF, Lei 9.424/96) e do Fundo de Manutenção de Desenvolvimento da Educação Básica (FUNDEB, Lei 11.494/07), cabe à União realizar a redistribuição das arrecadações de impostos, de acordo com o número de matrículas no Ensino Fundamental de cada município, garantindo um valor aluno/ano distribuído nacionalmente.

Os Estados e Municípios são responsáveis pelo Ensino Médio e pela Educação Infantil, respectivamente. A universalização da Educação Básica ficou sob a responsabilidade dos Municípios, juntamente com os Estados; compete ressaltar que o FUNDEB está em vigor desde janeiro de 2007 e se estende até 2020 (CASTRO, 2016). No Brasil, de acordo com o artigo 212, da Constituição Federal, e o artigo 70, da 
LDB, Lei 9.493/96, no que diz respeito à manutenção e desenvolvimento do ensino brasileiro, considera-se como despesas os gastos com salário e encargos empregatícios dos professores e especialistas, com a formação docente e dos servidores da escola, com a construção e manutenção de escolas, com estudos e pesquisas para a melhoria da qualidade escolar, com a aquisição de materiais para o desenvolvimento de atividades na escola, bolsas de estudo e transporte de alunos, incluindo a compra e manutenção de veículos (BRASIL, 2012).

Os três países oferecem ensino gratuito em pelo menos um dos níveis. Em Singapura, apenas o Ensino Fundamental é gratuito; no Brasil, a Educação Básica e; na Finlândia, a gratuidade da educação se estende do Ensino Básico ao Superior. Outra diferença entre os países reside no fato de que no Brasil e na Finlândia o financiamento da educação nas escolas públicas é feito unicamente pelo governo, e em Singapura as escolas públicas podem receber dinheiro de entidades privadas, principalmente em se tratando do financiamento de obras e construções.

Na Finlândia, os alunos, durante os estudos obrigatórios, recebem livros, cadernos, lápis e todo o material necessário. Em Singapura, os alunos também recebem material didático impresso, digital e audiovisual para complementar sua formação. Já o Brasil possui o Programa Nacional do Livro Didático (PNLD), que trata da distribuição de livros didáticos gratuitos para as escolas brasileiras, sendo totalmente financiado pelo Fundo Nacional de Desenvolvimento da Educação (FNDE); somente essa política pública movimenta, anualmente, mais de 1 bilhão de reais em recursos (GONÇALVES, 2017).

Assim como a Finlândia, o Brasil também possui políticas públicas que garantem o transporte escolar, por meio do Programa Nacional de Transporte Escolar (PNTE), e a alimentação escolar, através do Programa Nacional de Alimentação Escolar (PNAE). No caso dessas duas políticas públicas, parte do recurso provém da União e, em contrapartida, os Estados e Municípios têm que complementar os recursos e operacionalizar as políticas, conforme exposto no Quadro 2.

QUADRO 2: QUADRO COMPARATIVO DAS POLIITICAS PÚBLICAS DO BRASLL, DE SINGAPURA E DA FINLÂNDIA.

\begin{tabular}{|c|c|c|c|c|c|c|}
\hline País & $\begin{array}{c}\text { Gratuidade do } \\
\text { Ensino }\end{array}$ & $\begin{array}{c}\text { Faixa Etária } \\
\text { Obrigatória }\end{array}$ & $\begin{array}{l}\text { Financiamento } \\
\text { da Educação }\end{array}$ & $\begin{array}{c}\text { Livro } \\
\text { Didático }\end{array}$ & $\begin{array}{c}\text { Transporte } \\
\text { Escolar }\end{array}$ & $\begin{array}{c}\text { Alimentação } \\
\text { Escolar }\end{array}$ \\
\hline Brasil & Educação Básica & 4 - 17 anos & Público & Fornece & Disponibiliza & Disponibiliza \\
\hline Finlândia & $\begin{array}{c}\text { Educação } \\
\text { Básica e Ensino } \\
\text { Superior }\end{array}$ & $7-16$ anos & Público & Fornece & Disponibiliza & Disponibiliza \\
\hline Singapura & $\begin{array}{c}\text { Ensino } \\
\text { Fundamental }\end{array}$ & $6-15$ anos & $\begin{array}{l}\text { Público e } \\
\text { Privado }\end{array}$ & Fornece & $\begin{array}{c}\text { Não } \\
\text { disponibiliza }\end{array}$ & $\begin{array}{c}\text { Não } \\
\text { disponibiliza }\end{array}$ \\
\hline
\end{tabular}

FONTE: DADOS DA PESQUISA

\section{OS CURRÍCULOS ESCOLARES DO BRASIL, DE SINGAPURA E DA FINLÂNDIA}

Ao realizar a análise comparativa dos currículos escolares dos três sistemas educacionais em estudo, procurou-se construir um quadro de referências para subsidiar o debate sobre Políticas Públicas Educacionais implicadas na promoção do bom desempenho dos alunos no PISA, pela avaliação de como se dá a estruturação do currículo escolar de Ciências.

Em Singapura, o Ensino de Química ganha maior ênfase a partir do final do Ensino Básico. Além da Química vista em sala de aula, uma gama de programas complementa o currículo formal, tanto na escola quanto fora dela, tais como Feiras de Ciências, competições, trilhas de aprendizado, acampamentos, oficinas e atividades em institutos de pesquisa, objetivando envolver e inspirar os alunos em todos os níveis da educação. Existe uma estreita colaboração com parceiros, como a Agência de Ciência, Tecnologia e Pesquisa de Singapura, Institutos de Ensino Superior, Indústrias e o Centro de Ciências de Singapura, para projetar programas para estudantes de todos os níveis (OCDE, 2016a).

De fato, o governo de Singapura tem desenvolvido seu sistema educacional de acordo com as competências necessárias para o século XXI: alfabetização cívica, consciência global e habilidades 
transculturais, pensamento crítico e inventivo, habilidades de comunicação, colaboração e informação, competências sociais e emocionais - autoconsciência, autogestão, consciência social, gerenciamento de relacionamento e tomada de decisão responsável - e valores centrais de respeito, responsabilidade, integridade, cuidado, resiliência e harmonia. Por isso, a educação tem como objetivo ajudar os alunos a descobrir e tirar o melhor proveito de seus próprios talentos, realizar todo o seu potencial e desenvolver uma paixão pelo aprendizado que dure a vida toda (MINISTRY OF EDUCATION SINGAPORE, 2019).

Para o Ministério da Educação de Singapura, a globalização, as mudanças demográficas e os avanços tecnológicos são algumas das principais forças motrizes do futuro e, nesse contexto, os alunos deverão estar preparados para enfrentar esses desafios e aproveitar as oportunidades trazidas por essas forças. Para tal, é necessário que o conhecimento e as habilidades dos alunos sejam sustentados por determinados valores, pois estes moldam crenças, atitudes e ações de uma pessoa e, portanto, formam o núcleo da estrutura das competências do século XXI. Além disso, competências sociais e emocionais, ou seja, as habilidades necessárias para que as crianças reconheçam e gerenciem suas emoções, desenvolvam o cuidado e a preocupação com os outros, tomem decisões responsáveis, estabeleçam relações positivas e lidem com situações desafiadoras de maneira eficaz, também se fazem necessárias (MINISTRY OF EDUCATION SINGAPORE, 2019).

O currículo de Ciências da Educação Básica de Singapura centra-se no espírito científico e na investigação, baseando-se em três domínios essenciais para a prática da Ciência: 1) conhecimento, compreensão e aplicação; 2) habilidades e processos e; 3) ética e atitudes. O currículo visa a ajudar os alunos a valorizarem a busca da Ciência e apreciar o papel importante que esta desempenha na vida cotidiana e na sociedade (MINISTRY OF EDUCATION OF SINGAPORE, 2019).

O ensino básico finlandês obrigatório tem duração de nove anos (7-16 anos) e está dividido em lower stage (primeiro ao sexto ano) e upper stage (sétimo ao nono ano). O currículo é composto por aulas de língua nativa - que pode ser finlandês ou sueco -, Inglês, Matemática, Física, Química, Biologia, Geografia, História, Música, Artes Plásticas, Religião, Educação Física e para saúde (ROBERT, 2010). Depois do Ensino Básico, os estudantes podem escolher entre ensino secundário ou formação profissional, ambos com duração de três anos. Apenas 1\% dos alunos finlandeses, de 16 anos, não concluem o Ensino Básico obrigatório, e 95\% dos que concluem prosseguem para o Ensino Secundário (MONTEIRO, 2013). No país, os alunos aprendem sobre conceitos químicos desde o início da Educação Básica. Segundo Sothayapetch e Juuti (2013), este é um dos diferenciais da educação finlandesa e uma das razões pelas quais os estudantes têm se mantido entre melhores do PISA na área das Ciências.

De acordo com o currículo finlandês, o propósito do Ensino das Ciências é ajudar os alunos a: 1) perceberem a natureza das Ciências; 2) aprenderem novos conceitos, princípios e modelos científicos; 3) desenvolverem habilidades em trabalhos experimentais; 4) cooperarem e 5) tornarem-se estimulados e interessados a estudar Física e Química (NIEMI; TOOM; KALLIONIEMI, 2016).

Na Finlândia, o currículo da Educação Básica não apresenta muita variação entre as escolas, de forma que o conteúdo básico é comum para todos os alunos do país. Os aprendizes passam menos horas na sala de aula do que os alunos de outros países da OCDE: enquanto nos Estados Unidos os professores lecionam cerca de 1.080 horas de aula em um ano, na Finlândia esse número cai para 600 horas (KUPIAINEN; HAUTAMÄKI; KARJALAINEN, 2009). Entre os países da OCDE, o tempo de instrução obrigatória entre os 7 e 14 anos é de 6.777 horas; no entanto, esse tempo de instrução na Finlândia é de 1.025 horas a menos, um dos mais baixos da OCDE. Na Finlândia, espera-se que os alunos recebam, em média, 1.216 horas entre 7 e 8 anos, 2.049 entre 9 e 11 anos e 2.487 horas entre 12 e 14 anos de idade. As horas médias correspondentes na OCDE são de 1.554, 2.466 e 2.754 (OCDE, 2016b).

Para Bastos (2017), um acréscimo na carga horária dos alunos e a exigência de um elevado número de atividades escolares, ao invés de proporcionar aprendizagem, causa fadiga. Já Sahlberg (2011) destaca que países como a Finlândia, a Coreia do Sul e o Japão, nações com excelentes desempenhos nos testes do PISA, despendem menos horas em sala de aula, fazendo com que seus alunos frequentem, em média, até dois anos menos no ambiente escolar, quando comparados com estudantes de outros países. Segundo o Índice Global de Status do Professor, de 2018, da Varkey Foundation, um professor na Finlândia trabalha 38,6 horas por semana, no Brasil 47,7 horas e em Singapura 52 horas. 
Além disso, quando se comparam a idade em que as crianças são obrigadas, por lei, a frequentarem a escola, observa-se que os finlandeses começam três anos depois do que os brasileiros, aos 7 anos, e um ano depois dos alunos de Singapura - obrigados a irem para a escola aos 6 anos de idade. Os alunos brasileiros também precisam estudar mais anos de ensino obrigatório, dos 4 aos 17 anos, enquanto que finlandeses são obrigados a frequentar a escola dos 7 aos 16 anos, e os alunos de Singapura dos 6 aos 15 anos. Paradoxalmente, os finlandeses frequentam a escola por menos anos, despendem menos tempo em sala de aula e têm uma carga de tarefas escolares reduzida e, mesmo assim, têm resultados exitosos no PISA.

No Brasil, de acordo com a LDB, o ano letivo possui 200 dias, com quatro horas diárias. Segundo a BNCC, que entrou em vigor em 2020, o Ensino Médio terá um total de três mil horas, divididas em duas partes: 1.800 horas para Linguagens, Matemática, Ciências Humanas e Ciências da Natureza e 1.200 para os itinerários formativos. Na Finlândia, o ano letivo possui aproximadamente 190 dias, com cinco horas diárias, sendo dedicadas 1 hora e 10 minutos semanais para o Ensino de Química (NIEMI; TOOM; KALLIONIEMI, 2016). Em Singapura, são 200 dias letivos, cerca de seis horas diárias na escola e 3 horas semanais dedicadas ao Ensino de Química.

De forma análoga à Singapura, a Finlândia desenvolve a aproximação dos alunos das escolas da Educação Básica aos Laboratórios de Química ligados às universidades. Um destes laboratórios é o ChemistryLab Gadolinl ${ }^{1}$, da Universidade de Helsink, que serve como ambiente de apoio às aprendizagens e interesses dos alunos. Os objetivos do laboratório são oferecer visitas de estudo para grupos de estudantes com a possibilidade de realizarem atividades experimentais em um autêntico laboratório universitário, familiarizando os alunos com possibilidades de modelagem molecular computacional e promovendo o encontro com cientistas. As visitas de estudo são gratuitas para grupos de estudantes. Esses laboratórios também operam em estreita colaboração com indústrias e universidades, disponibilizando as informações mais recentes de pesquisas em Química (AHTEE; LAVONEN; PEHKONEN, 2018).

Já no Brasil, até o momento, não existem políticas públicas estruturadas como estas, para a interação entre universidades, indústrias e escolas públicas. Entretanto, o Ministério da Educação, em parceria com o Ministério da Ciência, Tecnologia, Inovações e Comunicações (MCTIC), lançou, em abril de 2019, o Programa Ciência na Escola (PCE), que a visa fortalecer a interação entre Instituições de Ensino Superior e as Escolas de Ensino Fundamental e Médio. Além desse programa, em 6 de novembro de 2019, o Ministério da Educação (MEC) impulsionou o Educação em Prática, em que as universidades receberão os alunos do Ensino Básico; as universidades disponibilizarão professores, laboratórios, salas de aula e quadras de esporte.

No currículo brasileiro, o Ensino de Química se desenvolve ao final do Ensino Fundamental e durante o Ensino Médio. Desde 2017, com a aprovação da BNCC, a Química foi incorporada aos estudos relacionados com as Ciências da Natureza. Segundo o documento, os objetivos das Ciências da Natureza são: 1) o compromisso com o desenvolvimento do letramento científico; 2) permissão do acesso aos conhecimentos científicos desenvolvidos ao longo do tempo e 3) aproximação, gradativa, dos alunos aos processos, práticas e procedimentos científicos (BRASIL, 2017).

Para a BNCC (2017), as competências da Ciências da Natureza para o Ensino Médio são:

1. Analisar fenômenos naturais e processos tecnológicos, com base nas interações e relações entre matéria e energia, para propor ações individuais e coletivas que aperfeiçoem processos produtivos, minimizem impactos socioambientais e melhorem as condições de vida em âmbito local, regional e global.

2. Analisar e utilizar interpretações sobre a dinâmica da Vida, da Terra e do Cosmos para elaborar argumentos, realizar previsões sobre o funcionamento e a evolução dos seres vivos e do Universo, e fundamentar e defender decisões éticas e responsáveis.

3. Investigar situações-problema e avaliar aplicações do conhecimento científico e tecnológico e suas implicações no mundo, utilizando procedimentos e linguagens próprios das Ciências da Natureza, para propor soluções que considerem demandas locais, regionais e/ou globais,

\footnotetext{
${ }^{1} \mathrm{O}$ ChemistryLab Gadolin oferece visitas de estudo ativas durante as quais grupos de instituições de ensino de diferentes níveis podem realizar experimentos de Química em um laboratório universitário real.
} 
e comunicar suas descobertas e conclusões a públicos variados, em diversos contextos e por meio de diferentes mídias e tecnologias digitais de informação e comunicação (TDIC) (BNCC, 2017, p. 553).

Quanto aos sistemas de avaliação, o sistema educacional de Singapura baseia-se em exames desde o final do Ensino Básico, em que os alunos realizam o exame Primary School Leaving Examination (PSLE), o qual avalia as habilidades dos alunos e define quais são suas opções e quais cursos se adequam ao seu aprendizado (MINISTRY OF EDUCATION SINGAPORE, 2019). No ensino secundário, os alunos passam por mais 3 exames, sendo eles o General Certificate of Education - Normal (GCE N), General Certificate of Education - Ordinary (GCE O) e o General Certificate of Education - Advanced (GCE A). Os alunos que atingem uma nota suficiente no GCE N são capazes de ingressar nos cursos do Instituto Técnico; com nota suficiente no GCE O podem ingressar nos cursos politécnicos e no junior college e, por fim; o GCE A permite a entrada nas universidades. Além dos alunos, os professores e as escolas também são avaliados: as instituições de ensino são incentivadas a concorrer no prêmio Singapore Quality Class (SCQ), o qual avalia temas como liderança, planejamento, informação, pessoas, processos, clientes e resultados (SEONG, 2008).

Esse sistema escolar extremamente competitivo faz com que os pais também se envolvam e se preocupem com a pontuação dos filhos. A obsessão dos pais está ligada majoritariamente ao teste que indicará o curso secundário mais adequado ao rendimento dos alunos. Sendo assim, existe uma grande cobrança e acompanhamento com relação à pontuação dos filhos, no acompanhamento dos temas de casa e no financiamento de aulas particulares. Segundo How (2015), cerca de 70\% dos estudantes acabam tendo um tutor particular, fato que também ocorre em outros países asiáticos, tais como a Coreia do Sul, em que 90\% dos alunos do ensino primário têm aulas particulares, e em Hong Kong, em que 85\% dos alunos no ensino secundário recebem o auxílio de tutores. Segundo o autor, todo esse estresse gera problemas de sono e má qualidade de vida nos estudantes.

Já a Finlândia não valoriza as avaliações internas e desestimula a comparação entre as escolas. O sistema finlandês distancia-se da responsabilização direta dos docentes nos resultados e estimula a cooperação entre os professores de uma mesma escola, e também entre escolas, para aprimorar as práticas docentes (KUIPER, BERKVENS, 2013). A avaliação tem a função de expor aos professores informações referentes ao desenvolvimento de sua ação pedagógica.

O Brasil, por sua vez, submete seus alunos a avaliações internas e externas, dentre elas a Provinha Brasil, o ENEM (Exame Nacional do Ensino Médio), o ENADE (Exame Nacional de Desempenho dos Estudantes) e o PISA. Pizarro (2017) defende que essas avaliações acabaram por se distanciar de sua proposta inicial, que seria oferecer dados para a reformulação da ação docente, e acabaram por desenvolver rankings e designar as boas e as más escolas.

\section{FORMAÇÃO INICIAL E SELEÇ̃̃O DOS PROFESSORES}

Autores como Corradini (2012), Pizarro (2017), Moraes (2017) e Lima (2018) apontam a formação e a valorização de professores como fatores importantes para os altos desempenhos dos estudantes no PISA. Assim, nessa seção apresentam-se dados referentes à formação de professores, ao rendimento salarial e aos benefícios e à seleção docente no Brasil, em Singapura e na Finlândia.

Singapura, desde o fim da década de 1990, com a Reforma Educacional denominada Thinking Schools, Learning Nation (1998), redefiniu o papel de seus professores, passando a valorizar a qualificação dos docentes. Desde então, o governo investe na qualidade de seu corpo docente, uma vez que acredita no papel protagonista do professor no desenvolvimento nacional (SHIGUNOV; FORTUNATO, 2017).

Ao longo dos anos, a formação de professores em Singapura passou da Faculdade de Formação de Professores (Teacher Training College) para uma entidade autônoma, o Instituto Nacional de Educação (National Institute of Education, NIE), dentro da Universidade Tecnológica Nanyang (Nanyang Technological University, NTU). Importante destacar que num recente ranking denominado QS World University, a NIE foi classificada como a décima quarta melhor universidade em educação no mundo 
(HU; LOH, 2019). Os cursos de licenciatura têm duração de 4 anos e são projetados para a educação acadêmica, bem como a formação profissional de estudantes de graduação. Dentro dos cursos, os futuros professores realizam um estágio que compreende quatro períodos de inserção na escola: experiência escolar, assistência de ensino e prática de ensino 1 e 2 (HU; LOH, 2019). A formação de professores de Química da NIE compreende disciplinas de Química Orgânica, Analítica, Inorgânica, Físico-Química, Polímeros, Química Verde, dos Alimentos, Ambiental e de Materiais.

Desde a década de 1970, a formação inicial de professores na Finlândia começou a ocorrer nas universidades, sendo requisito aos futuros professores da Educação Básica a formação à nível de mestrado (KUPIAINEN; HAUTAMÄKI; KARJALAINEN, 2009). Durante sua formação acadêmica, os futuros professores finlandeses, que desejam atuar nos anos finais do Ensino Fundamental e do Ensino Médio, desenvolvem sua formação na ênfase em que irão lecionar. Para atuar em qualquer ano do Ensino Básico, mesmo nos anos iniciais, o professor deve ter habilitação para, no mínimo, duas disciplinas escolares (minors), além da formação em Pedagogia (BASTOS, 2017).

O Brasil, desde a implementação da LDB de 1996, passou a exigir formação superior dos professores da Educação Básica. Contudo, o prazo de adequação a esta lei, atualmente, se estende até 2020, o que reflete em uma diversidade muito grande de formação, de acordo com a região do país. Além disso, a exigência de formação não veio acompanhada de valorização profissional e reconhecimento social (FERNANDEZ, 2018). Ademais, a Medida Provisória 746/2016, que visa à certificação de conhecimento aos professores da Educação Básica, em qualquer área do conhecimento, contempla que é possível lecionar, para qualquer nível de ensino, sem a necessidade da graduação em licenciatura, desde que o profissional apresente saber notório na área em que irá atuar (BRASIL, 2016).

A formação de professores para os anos finais do Ensino Fundamental e Médio no Brasil ocorre nas universidades públicas e privadas e institutos federais, nas modalidades presencial e a distância. Para atuar na Educação Infantil e nos anos iniciais do Ensino Fundamental, o professor deve ter formação em Pedagogia; já para atuar nos anos finais do Ensino Fundamental e no Ensino Médio é necessária a formação em Licenciatura, de acordo com a área de preferência. Diferentemente do que acontece na formação dos professores da Finlândia e de Singapura, segundo Fernandez (2018), a qualidade dos cursos de formação de educadores no Brasil varia muito entre as instituições.

Em Singapura, os futuros professores estão entre 30\% melhores alunos do Ensino Médio (BOON; GOPINATHAN, 2006; AHO; PITKÄNEN; SAHLBERG, 2006) No processo de seleção para o cargo, os candidatos também passam por entrevista com um painel de educadores seniores, incluindo funcionários do Instituto Nacional de Educação (MOURSHED; CHIJIOKE; BARBER, 2010). Na Finlândia, a carreira de professor é uma das mais concorridas. Os futuros docentes são escolhidos entre os melhores discentes do Ensino Médio e os cursos de formação de professores são gratuitos. Fernandez (2018) destaca que, para ser professor na Finlândia, os candidatos precisam ter uma postura positiva e competências interpessoais. Segundo a autora, 1 em cada 10 candidatos são selecionados para os cursos universitários de licenciatura, e os futuros professores residem entre os 10\% melhores alunos do Ensino Médio. O processo para se tornar um professor na Finlândia segue um caminho claro: passar no exame de conclusão do Ensino Médio, aplicar-se para o programa de treinamento de professores em uma das oito instituições públicas, participar de um exame de admissão em duas etapas, ser admitido e concluir o Mestrado em Educação (IZADI, 2019).

Já no sistema educacional brasileiro, o processo de seleção dos docentes é descentralizado. Dizendo de outro modo, cada Estado e Município, ou mesmo a Federação, seleciona os profissionais para atuarem em seu sistema de ensino, fazendo com que os processos de seleção não sejam únicos. A seleção de professores no Brasil, de maneira geral, ocorre na forma de concurso público, com prova escrita e/ou objetiva, além de prova de títulos do candidato, não incluindo uma prova prática de didática ou entrevista.

Corroborando com essa análise, um estudo realizado por Fuchs e Wößmann (2007), que procura explicar as diferenças internacionais no desempenho dos alunos através dos dados do PISA, demonstra que os discentes de escolas cujos professores tiveram, em média, um nível superior de educação (incluindo graduação e pós-graduação), apresentam desempenhos significativamente melhores do que os alunos cujos professores tiveram menos anos de formação superior, principalmente em se tratando de Matemática e Ciências. Além disso, os processos de seleção da Finlândia e de Singapura consideram os 
resultados acadêmicos dos candidatos, suas competências de comunicação e a intenção para atuar enquanto professor (BOON; GOPINATHAN, 2006; AHO; PITKÄNEN; SAHLBERG, 2006).

O salário inicial anual de um professor do Ensino Médio em Singapura é de mais de 50.000 USD, na Finlândia 40.000 USD e no Brasil 13.000 USD, segundo dados do Índice Global de Status do Professor de 2018, da Varkey Foundation.

Em Singapura, os professores, além do maior salário, têm direito a programas e benefícios governamentais, incluindo habitação. Os resultados da pesquisa Pesquisa Internacional sobre Ensino e Aprendizagem de 2013 (Teaching and Learning International Survey, TALIS) da OCDE indicam que, globalmente, 91,2\% dos professores do Ensino Médio da Finlândia estavam satisfeitos com seu trabalho (PARONEN; LAPPI, 2018).

Já no Brasil, os salários baixos representam uma das causas da insatisfação profissional, conforme demonstra a pesquisa Profissão Docente - 2018, realizada pelo Todos pela Educação, Itaú Social e IBOPE (IBOPE, 2018). Segundo a pesquisa, apenas 23\% dos mais de 2000 professores entrevistados responderam que indicariam a profissão docente para os jovens. Outras causas para a insatisfação seriam a desvalorização da carreira e a falta de infraestrutura. Importante destacar que, dados do PISA coletados pela OCDE, demonstram que nações que possuem uma carreira docente atrativa e competitiva apresentam desempenho acima da média na OCDE (WHELAN, 2013).

No Quadro 3 pode-se observar as principais características da formação e da seleção de professores nas três nações estudadas.

QUADRO 3: QUADRO COMPARATIVO DE FORMACÃ̃O INICIAL E SELEÇÃO DE PROFESSORES NO BRASLL, SINGAPURA E FINLÂNDIA.

\begin{tabular}{|c|c|c|c|c|c|}
\hline País & Processo seletivo & $\begin{array}{l}\text { Salários } \\
\text { anuais } \\
\text { (USD) }\end{array}$ & $\begin{array}{c}\text { Nível de } \\
\text { escolaridade exigido }\end{array}$ & Tempo de curso & $\begin{array}{l}\text { Modalidade das } \\
\text { instituições de } \\
\text { formação }\end{array}$ \\
\hline Brasil & $\begin{array}{l}\text { Concurso com prova } \\
\text { escrita objetiva e prova } \\
\text { de títulos }\end{array}$ & 13.000 & $\begin{array}{l}\text { Graduação em } \\
\text { Licenciatura. } \\
\text { Curso Normal. } \\
\text { Notório saber. }\end{array}$ & $\begin{array}{c}\text { Graduação - } 4 \text { anos } \\
\text { Normal - } 3 \text { anos }\end{array}$ & $\begin{array}{l}\text { Pública e } \\
\text { Privada }\end{array}$ \\
\hline Singapura & $\begin{array}{l}\text { Exame de conclusão do } \\
\text { Ensino Médio. } \\
\text { Exame de admissão em } \\
\text { duas etapas. } \\
\text { Conclusão do Mestrado } \\
\text { em Educação. }\end{array}$ & 50.000 & $\begin{array}{l}\text { Graduação em } \\
\text { Licenciatura }\end{array}$ & 4 anos & Privada \\
\hline Finlândia & $\begin{array}{l}\text { Entrevista com um } \\
\text { painel de educadores } \\
\text { seniores, incluindo } \\
\text { funcionários do Instituto } \\
\text { Nacional de Educação. }\end{array}$ & 40.000 & Mestrado & 6 anos & Pública \\
\hline
\end{tabular}

\section{CONSIDERAÇ̃̃ES FINAIS}

Esta pesquisa abordou as Políticas Públicas Educacionais implementadas no Brasil, em Singapura e na Finlândia, estabelecendo um quadro comparativo para tentar identificar aspectos que possam ser considerados relevantes para o sucesso dos alunos no PISA 2015, na área das Ciências. O foco das análises foram os Sistemas Educacionais, a estrutura e os investimentos em educação, o currículo escolar, a formação inicial e a seleção dos professores. As políticas desenvolvidas nessas nações servem como um referencial valioso para o (re)pensar das Políticas Públicas Educacionais brasileiras. Para tanto, o estudo comparativo envolveu o levantamento de documentos legais dos países estudados, artigos científicos, teses e dissertações sobre o PISA, além de documentos e relatórios da OCDE. 
De acordo com as análises realizadas, os achados da pesquisa demonstraram que os países estudados com bom desempenho no PISA: a) possuem sistemas educativos descentralizados e apresentam flexibilidade nos currículos; b) investem mais em educação, aplicando mais do 9.000 USD por estudante; c) fortalecem a interação entre escolas de Educação Básica e universidades para o aprimoramento do ensino de Química; d) priorizam a qualidade da formação docente; e) pagam melhores salário aos professores; f) fazem da carreira docente mais atraente, gerando grande concorrência e captação dos melhores alunos; g) mostram que a descentralização finlandesa e de Singapura está aliada a um aumento da qualidade da formação docente e dos gestores escolares, enquanto a brasileira está ligada à divisão e distribuição de recursos; h) evidenciam que os alunos finlandeses frequentam a escola por menos dias letivos e têm quatro anos a menos de ensino obrigatório do que os brasileiros; i) mostram que os professores finlandeses são os que trabalham menos horas semanais e os docentes de Singapura os que trabalham mais e; j) elucidam que os alunos de Singapura, além de frequentarem a escola diariamente por mais horas, ainda frequentam aulas particulares.

A partir do estudo comparativo entre as Políticas Públicas Educacionais brasileiras, de Singapura e da Finlândia, a primeira lição que o Brasil pode aprender é que se deve investir no professor, na qualificação da sua formação inicial, no aumento salarial e na valorização profissional, para tornar a carreira docente mais atrativa, possibilitando aos profissionais mais satisfação com a função que exercem. Para alcançar sucesso nas avaliações internacionais, o Brasil precisa, ainda, investir mais em educação, no mínimo 6.000 USD por estudante. Outra questão a ser revista, devido aos bons resultados na Finlândia e Singapura, é a ampliação de programas de interação universidade e escola. Diante do exposto, acredita-se que devido à repercussão dos resultados do PISA e em virtude do desempenho dos alunos brasileiros nessa avaliação, fazem-se necessários mais estudos que abordem as Políticas Públicas Educacionais implicadas no sucesso dos alunos brasileiros.

\section{REFERÊNCIAS}

AHO, E.; PITKÄNEN, K; SAHLBERG, P. Policy development and reform principles of basic and secondary education in Finland since 1968. Washington: World Bank, 2006.

AHTEE; M.; LAVONEN, J.; PEHKONEN, E. Reasons behind the finnish success in science and mathematics in PISA tests. Problems of Education in the 21st Century, v. 6, p. 18-26, 2018.

AMARAL, N. C. Os 10\% do PIB como promotor da qualidade da educação: uma análise considerando os resultados do PISA e os valores aplicados por estudante em diversos países. In: GOUVEIA, A. B.; REZENDE PINTO, J. M.; FERNANDES, M. D. E. (Org.). Financiamento da educação no Brasil: os desafios de gastar 10\% do PIB em dez anos... Campo Grande: Oeste, v. 1, p. 61-82, 2015.

AVILA, A. P. C.; HUI, C.; LAM, A., TAN, J. Pisa: Lessons for and from Singapore. Singapura: National Institute of Education, 2012. 33 p.

BASTOS, R. M. B. O surpreendente êxito do sistema educacional finlandês em um cenário global de educação mercantilizada. Revista Brasileira de Educação, v. 22, n. 70, p. 802-825, jul/set. 2017.

BOON, G.; GOPINATHAN, S. The developmente of educations in Singapore. Singapura: National Institute of Education, 2006. 33p.

BRASIL. MEC. Base Nacional Comum Curricular. Brasília: MEC. 2017. 472p.

BRASIL. INEP. PISA 2000: Relatório Nacional. Brasília: INEP, 2001. 88p.

BRASIL. INEP. Resultados Nacionais: PISA 2006. Brasília: INEP, 2008. 154p.

BRASIL. Institui a Política de Fomento à Implementação de Escolas de Ensino Médio em Tempo Integral. Altera a Lei no 9.394, de 20 de dezembro de 1996, que estabelece as diretrizes e bases da educação nacional. Disponível em: https://www.congressonacional.leg.br /materias /medidasprovisorias/-/mpv/126992. Acesso em: 15 out. 2019. 
BRASIL. Lei no 4.024/61. Fixa as Diretrizes e Bases da Educação Nacional. Disponível em: http:// www.planalto.gov.br/ccivil_03/leis/14024.html. Acesso em: 20 out. 2019.

BRASIL. Lei no 9.394/96. Estabelece as Diretrizes e Bases da Educação Nacional. Disponível em: www6.senado.gov.br/.../ListaTextoIntegral.action?id. Acesso em: 27 out. 2019.

BRASIL. Lei n ${ }^{0}$ 9.424/1996. Dispõe sobre o Fundo de Manutenção e Desenvolvimento do Ensino Fundamental e de Valorização do Magistério, Disponível em: http://www.planalto.gov.br/CCIVIL_03/ leis/L9424.htm. Acesso em: 24 out. 2019.

BRASIL. Lei no 11.494/2007. Regulamenta o Fundo de Manutenção e Desenvolvimento da Educação Básica e de Valorização dos Profissionais da Educação - FUNDEB. Disponível em: www.planalto.gov. br/ccivil03/ato2007- 2010/2007/lei/111494.htm. Acesso em: 16 ago. 2019.

BRASIL. Lei no 13.005/2014. Aprova o Plano Nacional de Educação - PNE. Disponível em: http:// www.planalto.gov.br/ccivil_03/_ato2011-2014/2014/lei/l13005.htm. Acesso em: 16 ago. 2019.

BRASIL. Tribunal de Contas do Estado de São Paulo. O Tribunal e a Gestão Financeira dos Prefeitos. 2012. Disponível em: https://www4.tce.sp.gov.br/sites/default/files/images /manual-gestaofinanceira prefeitura-municipal.pdf. Acesso em: 15 out. 2019.

BRASIL. UNICEF. Fundo das Nações Unidas para a Infância. Relatório \#ECA25anos - Avanços e Desafios para a Infância e a Adolescência. Disponível em: http://www.unicef.org/brazil/pt/ media_30280.htm. Acesso em: 21 out. 2019.

CARVALHO, L. M. Governando a educação pelo espelho do perito: uma análise do pisa como instrumento de regulação. Educ. Soc., v. 30, n. 109, p. 1009-1036, 2009.

CARVALHO, L. M. PISA, policy and knowledge in education. Educ. Soc., v. 37, n. 136, p.601-607, 2016.

CARVALHO, L. M. The Fabrication and Travel of a Knowledge-Policy Instrument. European Educational Research Journal, v. 11, n. 2, p. 172-188, 2012.

CASTRO, M. H. G. Características gerais do PISA, principais resultados e critérios de escolha dos países. Rio de Janeiro: CNI, 2010. 164p.

CASTRO, M. H. G. O Saeb e a agenda de reformas educacionais: 1995 a 2002. Em Aberto, v. 29, n. 96, p. 85-98, 2016.

CHIA, Y. Education, Culture and the Singapore Developmental State: "WorldSoul” Lost and Regained? Palgrave Macmillan, 2015. 277p.

CORRADINI, S. N. Indicadores de qualidade na Educação: um estudo a partir do PISA e da TALIS. 2012. 309f. Tese (Doutorado em Ciências Humanas) - Universidade Federal de São Carlos, São Carlos, 2012.

FERNANDEZ, C. Formação de professores de Química no Brasil e no mundo. Estud. av., v. 32, n. 94, p. 205-224, 2018.

FERREIRA, A. G. O sentido da educação comparada: uma compreensão sobre a construção de uma identidade. In: SOUZA, D. B.; MARTINEZ, S. A. (Orgs.). Educação comparada: rotas de além-mar. São Paulo: Xamã, 2009. p. 137-166.

FINNISH NATIONAL AGENCY FOR EDUCATION. Basic Education Act., 1998. Disponível em: http://www.finlex.fi/en/laki/kaannokset/1998/en19980628.pdf. Acesso em: 19 set. de 2019.

FUCHS, T.; Wößmann, L. What accounts for international differences in student performance? A reexamination using PISA data. Empirical Econmics, v. 32, n. 2-3, p. 43-464, 2004. 
GONÇALVES, P. C. C. Políticas públicas de livro didático: elementos para compreensão da agenda de políticas públicas em educação no Brasil. 2017. 233f. Tese de Doutorado. Faculdade de Educação, Universidade Federal de Uberlândia. Uberlândia, 2017.

HOW, T. T. Is it time for a new approach to education in Singapore: Towards Education for a Flourishing Life. Singapura: The Head Foundation, 2015. 13p.

HU, G; LOH, J. Teacher Education in Singapore. Oxford: Oxford University Press, 2019. 23p.

IBOPE. Pesquisa Profissão Professor - 2018. Disponível em: https://www.itausocial.org.br/noti cias/ professores-consideram-qualificacao-e-escuta-como-as-principais-medidas-para-valorizar-a-profissao/. Acesso em: 13 out. 2019.

IZADI, R. Teacher selection in Finland. Does academic ability predict teacher aptitude? Aalto University, 2019. Disponível em: http://conference.iza.org/conferenc e_files /SUM_2019/izadi_r2 8090.pdf. Acesso em: 13 out. 2019.

JERRIM, J. Why do East Asian children perform so well in PISA? An investigation of Western-born children of East Asian descent. Oxford Review of Education, v. 41, n. 3, p. 310-333, 2015.

KUIPER, W.; BERKVENS, J. Balancing Curriculum Regulation and Freedom across Europe. Enschede: Gildprint, 2013. 288p.

KUPIAINEN, S.; HAUTAMÄKI, J.; KARJALAINEN, T. The finnish education system and PISA. Helsinki: Ministry of Education Publications, 2009. 61p.

LEE, D. H. L.; HONG, H.; NIEMI, H. A Contextualized Account of Holistic Education in Finland and Singapore: Implications on Singapore Educational Context. Asia-Pacific Edu Res., v. 23, n. 4, p. 871-884, 2014.

LIMA, V. M. Competências e habilidades em questões do PISA: evidências na realidade do Ensino de Ciências em escolas de Porto Alegre e região metropolitana. 2018. 95f. Dissertação (Mestrado) Programa de Pós-Graduação em Educação em Ciências e Matemática, PUCRS, Porto Alegre, 2018.

MARCHELLI, P. S. Da LDB 4.024/61 ao debate contemporâneo sobre as bases curriculares nacionais. Revista e-Curriculum, v. 12, n. 3, p. 1480-1511, 2014.

MARÔCO, J.; GONÇALVES, V.; LOURENÇO, V.; MENDES, R. PISA 2015 - PORTUGAL. Volume I: Literacia Científica, Literacia de Leitura \& Literacia Matemática. Gráfica Manuel Barbosa \& Filhos: Lisboa, 2016. 136p.

MATOS, D. A. B; FERRÃO, M. E. Repetência e indisciplina: evidências de Brasil e Portugal no Pisa 2012. Cadernos de Pesquisa, v. 46, n. 161, p. 614-636 jul/set., 2016.

MEINANDER, H. A History of Finland. London: C. Hurst \& Company Ltda., 2011. 227p.

MINISTRY OF EDUCATION FINLAND. Finnish National Agency for Education, 2018. Disponível em: https://www.oph.fi/english. Acesso em: 20 mai. 2019.

MINISTRY OF EDUCATION SINGAPORE. Compulsory Education Act, 2000. Disponível em: https://sso.agc.gov.sg/Act/CEA2000\#pr8-. Acesso em: 20 mai. 2019.

MINISTRY OF EDUCATION SINGAPORE. Education. Disponível em: https://www.moe. gov.sg/ education. Acesso em: 20 mai. 2019.

MONTEIRO, A. R. Finlândia: um sistema de educação admirável. Poiésis, v. 7, n. 11, p. 26-39, 2013.

MORAES, C. S. V. O Ensino Médio e as comparações internacionais: Brasil, Inglaterra e Finlândia.

Educ. Soc., v. 38, n. 139, p. 405-429, 2017. 
MOURSHED, M.; CHIJIOKE, C.; BARBER, M. How the world's most improved school systems keep getting better. London: McKinsey \& Co. 2010.

NÓVOA, Antonio. Modelos de análise em educação comparada: o campo e a carta. Les Sciences de l'education pour l'ère nouvelle, n. 2, v.3, 1995.

NIEMI, H.; TOOM, A.; KALLIONIEMI, A. Miracle of Education. Helsinki: Sense Publishers, 2016. 294p.

OCDE. Education at a Glance 2010. OCDE Publishing: Paris, 2010a. 134p.

OCDE. Education Policy Outlook 2015: making reforms happen. OECD Publishing: Paris, 2015. 316p.

OCDE. First Results from PISA 2003. OCDE Publishing: Paris, 2004. 44p.

OCDE. PISA 2009 Results: Executive Summary. OCDE Publishing: Paris, 2010b. 21p.

OCDE. PISA 2012 Results in Focus: What 15-year-olds know and what they can do with what they know. OCDE Publishing: Paris, 2014. 44p.

OCDE. PISA 2015 Assessment and Analytical Framework. Paris: OCDE, 2017. 262p.

OCDE. PISA 2015 High Performers: Country Note - Singapore. Paris: OCDE, 2016a. 6p.

OCDE. PISA 2015 Results: excellence and equity in education. v. 1. Paris: OCDE, 2016b. 494p.

OCDE. Take the Test Sample: Questions from OECD’s PISA Assessments. Paris: OCDE, 2018. 322p.

ORTIGÃO, M. I. R.; AGUILAR JÚNIOR, C. A.; ZUCULA, A. F. Analisando a repetência escolar a partir de dados do PISA 2012. In: VI SIPEM - $7^{\circ}$ Simpósio Internacional de Pesquisa em Educação Matemática. Anais [...] Pirenópolis - GO: VI SIPEM, 2015. Disponível em: http://www.sbembrasil. org.br. Acesso em: 20 mai. 2019.

PARONEN, P.; LAPPI, O. Finnish teachers and principals in figures. Helsinki: Juvenes Print, 2018.

PASINATO, N. M. B. Integração das TDIC na formação de professores em Cingapura: entre intenções, ações e concepções. 2017. 256f. Tese (Doutorado em Educação: Currículo) - Programa de Estudos Pós-Graduados em Educação: Currículo, Pontifícia Universidade Católica de São Paulo, São Paulo, 2017.

PIZARRO, M. V.; LOPES, J. Os sistemas de avaliação em larga escala e seus resultados: o PISA e suas possíveis implicações para o ensino de ciências. Ens. Pesqui. Educ. Ciênc., v. 19, p. 1893-2117, 2017.

ROBERT, P. A Educação na Finlândia, os segredos de um sucesso. Edições Afrontamento: 2010.

SAHLBERG, P. Finnish lessons: what can the world learn from educational change in Finland? New York: Teachers College, 2011.

SAHLBERG, P. Finnish lessons 2.0: What can the world learn from educational change in Finland? New York: Teachers College, 2015.

SASSAKI, A. H.; DI PIETRA, G.; MENEZES FILHO, N.; KOMATSU, B. Por que o Brasil vai Mal no PISA? Uma Análise dos Determinantes do Desempenho no Exame. Insper - Policy Paper, n. 31, p. 1-24, jun. 2018.

SEONG, D. N. F. Toward a better future: education and training for economic development in Singapore since 1965. Washington: Banco Mundial, 2008. 206p. 
SHIGUNOV, A; FORTUNATO, I. Educação Superior e Formação de Professores: questões atuais. São Paulo: Edições Hipótese, 2017. 180p.

SILVA, F. C. T. Estudos comparados como método de pesquisa: a escrita de uma história curricular por documentos curriculares. Rev. Bras. Educ., Rio de Janeiro, v. 21, n. 64, p. 209-224, 2016.

SOTHAYAPETCH, P.; LAVONEN, J.; JUUTI, K. A comparative analysis of PISA scientific literacy framework in Finnish and Thai science curricula. Science Education International. v. 24, n. 1, p. 7897, 2013.

USTUN, U.; ERYILMAZ, A. Analysis of Finnish Education System to question the reasons behind Finnish success in PISA. Studies in Educational Research and Development, v. 2, n. 2, p. 93-114, 2018.

VILELA-RIBEIRO, E. B.; BENITE, A. M. C. A crise de eficiência da escola para além de seus muros: a influência dos capitais social, cultural e econômico no desempenho escolar em ciências. Ciênc. educ., v. 23, n. 2, p. 403-418, 2017.

VILLANI, M.; OLIVEIRA, D. A. Avaliação Nacional e Internacional no Brasil: os vínculos entre o PISA e o IDEB. Educação \& Realidade, v. 43, n. 4, p. 1343-1362, 2018.

VOLMARI, K. Basic Education in the Nordic Region. Helsinki: Finnish National Agency for Education, 2019.

VÄLIJÄRVI, J.; LINNAKYLA, P.; KUPARI, P.; REINIKAINEN, P.; ARFFMAN, I. The Finnish success in PISA - and some reasons behind it. Kirjapaino Oma: Jyväskylä, 2007. 72p.

WHELAN, Fenton. Lessons Learned: How good policies produce better schools. Londres: Acasus, 2013. 224p. 